CLINICAL STUDY

\title{
Relationship between serum TSH levels and intrarenal hemodynamic parameters in euthyroid subjects
}

\author{
Akihiro Tsuda $^{1,2}$, Masaaki Inaba ${ }^{1,2}$, Mitsuru Ichii ${ }^{1,2}$, Akinobu Ochi ${ }^{1,2}$, Yoshiteru Ohno ${ }^{1,2}$, Shinya Nakatani ${ }^{1,2}$, \\ Shinsuke Yamada ${ }^{1,2}$, Katsuhito Mori ${ }^{1,2}$, Hideki Tahara ${ }^{1,2}$ and Eiji Ishimura ${ }^{1,2}$ \\ Departments of ${ }^{1}$ Nephrology and ${ }^{2}$ Metabolism, Endocrinology and Molecular Medicine, Osaka City University Graduate School of Medicine, 1-4-3, \\ Asahi-machi, Abeno-ku, Osaka 545-8585, Japan
}

(Correspondence should be addressed to A Tsuda; Email: naranotsudadesu@infoseek.jp)

\begin{abstract}
Objective: Low thyroid function may be associated with a reduced glomerular filtration rate (GFR) calculated on the basis of creatinine metabolism. Thyroid hormone directly affects serum creatinine in muscle and low thyroid function might exert a similar direct effect in the kidney. The goal of the study was to evaluate this possibility by assessment of the inulin-based GFR and to examine the mechanism underlying the reduction of GFR.

Patients and methods: Renal and glomerular hemodynamics were assessed by simultaneous measurements of plasma clearance of para-aminohippurate $\left(\mathrm{C}_{\mathrm{PAH}}\right)$ and inulin $\left(\mathrm{C}_{\mathrm{in}}\right)$ in 26 patients with serum creatinine $<1.00 \mathrm{mg} / \mathrm{dl}$ and without thyroid disease. All subjects were normotensive with or without antihypertensive treatment and were kept in a sodium-replete state. Renal and glomerular hemodynamics were calculated using Gomez's formulae.

Results: Serum TSH, including within the normal range $(0.69-4.30 \mu \mathrm{IU} / \mathrm{ml})$, was positively correlated with vascular resistance at the afferent arteriole $\left(R_{\mathrm{a}}\right)(r=0.609, P=0.0010)$, but not at the efferent arteriole $\left(R_{\mathrm{e}}\right)$. Serum TSH was significantly and negatively correlated with renal plasma flow (RPF), renal blood flow (RBF), and GFR $(r=-0.456, P=0.0192 ; r=-0.438, P=0.0252 ; r=-0.505$, $P=0.0086$ respectively). In multiple regression analysis, serum TSH was significantly positively associated with $R_{\mathrm{a}}$ after adjustment for age and mean blood pressure.

Conclusions: These findings suggest that low thyroid function, even within the normal range, is associated with reduced RPF, RBF, and GFR, which might be caused by a preferential increase in $R_{\mathrm{a}}$.
\end{abstract}

European Journal of Endocrinology 169 45-50

\section{Introduction}

Clinically overt and subclinical hypothyroidism is associated with a high rate of chronic kidney disease (CKD) $(1,2,3,4,5,6,7)$ and is an established cardiovascular risk factor (1). Subclinical hypothyroidism occurs in $5-15 \%$ of the general population and is highly prevalent in women over 60 years of age $(1,2)$. We have found that patients with this condition have a significantly increased pulse wave velocity (PWV) (8), which suggests that subclinical hypothyroidism is a significant and independent cardiovascular risk factor (4), although the mechanism is uncertain. As these patients become older, the prevalence of CKD, a definite cardiovascular risk factor, increases along with an agerelated increase in serum TSH levels (9).

A high serum TSH, even within its reference range, was recently found to be associated with a reduced glomerular filtration rate (GFR) calculated from formulae based on creatinine levels in serum and urine (6). Alteration in thyroid function affects muscle metabolism and may influence the creatinine-based
GFR, independently of its effect on the kidney, through an effect on metabolism of creatinine, which preferentially localizes in type II fibers in the muscle (10). Therefore, high serum TSH, even within the normal range, might directly suppress renal function and contribute to acceleration of atherosclerotic changes in subclinical hypothyroidism.

In this study, we examined the relationship of subtle changes in serum TSH within the normal range with inulin clearance $\left(C_{i n}\right)$, which is normally used for measurement of GFR. To examine the mechanism through which high serum TSH might reduce GFR, we simultaneously measured para-aminohippurate (PAH) clearance $\left(\mathrm{C}_{\mathrm{PAH}}\right)$.

\section{Patients and methods}

\section{Study design and patients}

The study protocol was approved by the Ethics Committee of Osaka City University Graduate School of Medicine. The study was performed as a single-center 
study at Osaka City University Hospital between January 2010 and August 2011. Written informed consent was obtained from each patient.

The subjects were 26 patients $(55.4 \pm 14.7$ years old, 8 males and 18 females) who were admitted to Osaka City University Hospital for a medical checkup. Of these patients, 21 had diabetes, but none exhibited macroalbuminuria and all had a serum creatinine level $<1.00 \mathrm{mg} / \mathrm{dl}$. The mean serum TSH level was 1.720 $\pm 0.885 \mu \mathrm{IU} / \mathrm{ml}$ and all patients were within the normal range of $0.69-4.30 \mu \mathrm{IU} / \mathrm{ml}$. Serum-free thyroxine $\left(\mathrm{FT}_{4}\right)$ and free triiodothyronine $\left(\mathrm{FT}_{3}\right)$ levels were also within the respective normal limits of 1.20 $\pm 0.182 \mathrm{ng} / \mathrm{dl}$ and $2.92 \pm 0.38 \mathrm{pg} / \mathrm{ml}$.

\section{Measurement of $C_{\text {in }}$ and $C_{P A H}$ and calculation of intrarenal hemodynamic parameters}

Renal plasma flow (RPF) and GFR were determined by the constant input clearance technique using $\mathrm{PAH}$ and inulin respectively. As shown in Fig. 1, continuous i.v. infusion of $1 \%$ inulin and $0.5 \% \mathrm{PAH}$ from the antecubital vein was performed in the morning after an overnight fast, based on the method of Horio et al. (11). $C_{\text {in }}$ and $C_{\mathrm{PAH}}$ were simultaneously measured using
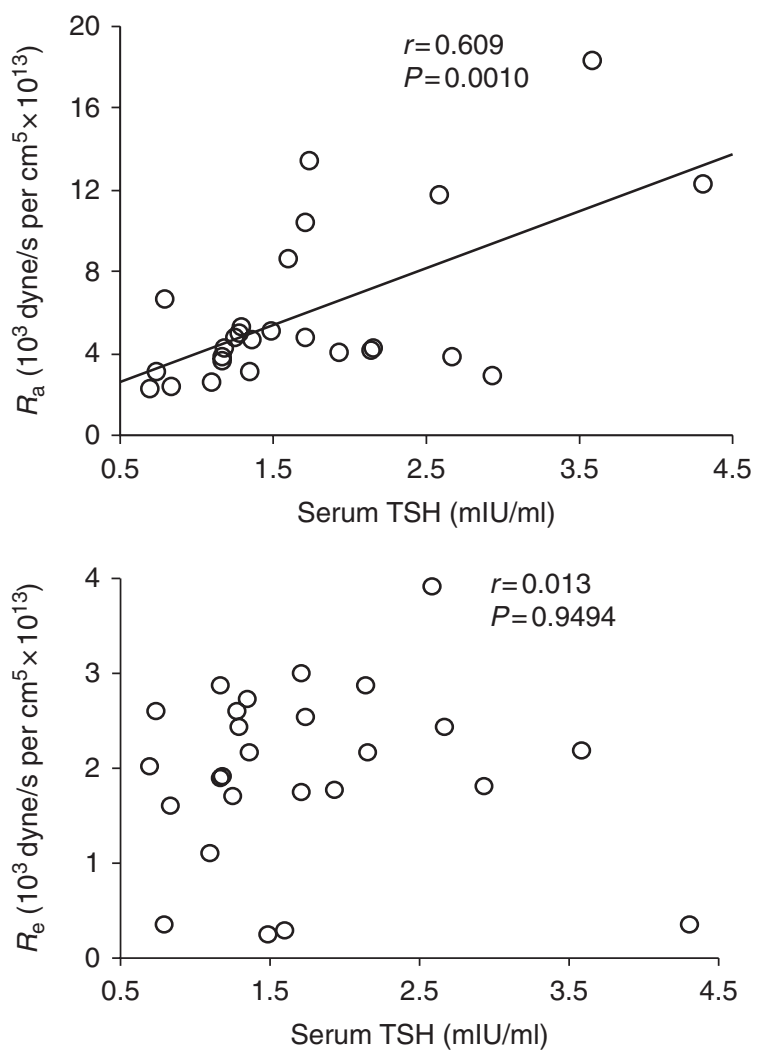

Figure 1 Relationship between serum TSH, afferent arteriolar resistance $(\mathrm{Ra})$ and efferent arteriolar resistance $(\mathrm{Re})$. Serum TSH had a significant positive correlation with $R_{\mathrm{a}}(r=0.609, P=0.0010)$ but showed no correlation with $R_{\mathrm{e}}(r=0.013, P=0.9494)$. a simple method based on a single urine collection. In brief, patients received $500 \mathrm{ml}$ water orally $15 \mathrm{~min}$ before infusion. After a priming dose of PAH and inulin, the rates of infusion were set at $300 \mathrm{ml} / \mathrm{h}$ for the first $30 \mathrm{~min}$ and $100 \mathrm{ml} / \mathrm{min}$ for the remaining time. To maintain hydration, $180 \mathrm{ml}$ water was given. Patients completely emptied the bladder at 45 min after the start of the test and urine was collected for measurement of urinary inulin and PAH. The urine collection period was set at $90 \mathrm{~min}$ to increase the accuracy of the clearance study. Blood samples for measurement of serum inulin and $\mathrm{PAH}$ were taken at the beginning and end of the clearance period.

$\mathrm{C}_{\text {in }}$ and $\mathrm{C}_{\mathrm{PAH}}$ were calculated by the $U V / P$ method ( $U$, concentration in urine; $V$, urine volume $(\mathrm{ml} / \mathrm{min})$; $P$, concentration in plasma) using the mean of the serum inulin concentrations at the beginning and end of the clearance period. Plasma $\mathrm{PAH}$ and inulin concentrations were determined colorimetrically using the $N-1$ naphthylethylenediamine and anthrone method respectively, with a Corning 258 spectrophotometer $(4,12,13)$. The clearance values were not corrected for body surface area, partly because Turner \& Reilly (14) have shown that adjusting renal hemodynamic variables for body surface may lead to inappropriate inferences and obscure gender-related differences.

Direct measurement of glomerular hemodynamics parameters in humans is not feasible, but formulae introduced by Gomez (15) (Table 1) allow indirect assessment of glomerular hemodynamics, as recently discussed in detail by Guidi et al. (16). These formulae were designed for quantitative estimation of filtration pressure across the glomerular capillaries $\left(\Delta P_{\mathrm{F}}\right)$, glomerular hydrostatic pressure $\left(P_{\text {glo }}\right)$, and afferent and efferent glomerular resistances $\left(R_{\mathrm{a}}\right.$ and $R_{\mathrm{e}}$ respectively) using measured blood pressure, GFR measured by $\mathrm{C}_{\mathrm{in}}$, RPF measured by $\mathrm{C}_{\mathrm{PAH}}$, hematocrit, and plasma protein concentrations under the assumptions that: i) intrarenal vascular resistances can be divided into three compartments: afferent, efferent, and venular; ii) hydrostatic pressures in the venules, interstitium, renal tubules, and Bowman's space $\left(P_{\text {Bow }}\right)$ are in equilibrium at a value of $\sim 10 \mathrm{mmHg}$; iii) the gross filtration coefficient $\left(K_{\mathrm{FG}}\right)$ is $0.0406 \mathrm{ml} / \mathrm{s}$ per $\mathrm{mmHg}$ per kidney; and iv) a filtration disequilibrium is postulated along the glomerular capillaries $(15,16)$.

From Ohm's law:

$R_{\mathrm{a}}=\left(\left(\mathrm{MBP}-P_{\mathrm{glo}}\right) / \mathrm{RBF}\right) \times 1328$.

$R_{\mathrm{e}}=\left(\mathrm{GFR} / K_{\mathrm{FG}}(\mathrm{RBF}-\mathrm{GFR})\right) \times 1328$.

In these equations, 1328 is the conversion factor to dyne/s per $\mathrm{cm}^{5}$ and GFR, RPF, and renal blood flow $(\mathrm{RBF})$ are expressed in $\mathrm{ml} / \mathrm{s}$.

\section{Statistical analysis}

Results are expressed as means \pm s.D. Correlations between two variables were examined using Spearman's correlation coefficient. Multiple regression analyses 
Table 1 Gomez's formulae.

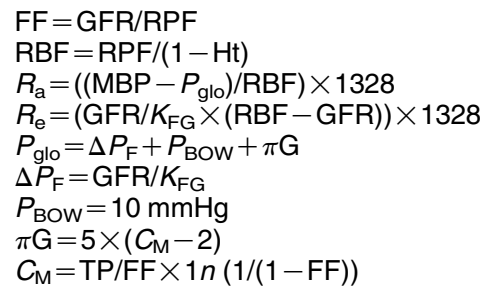

GFR, glomerular filtration rate $(\mathrm{ml} / \mathrm{min})$; RPF, renal plasma flow $(\mathrm{ml} / \mathrm{min})$ $\mathrm{RBF}$, renal blood flow ( $\mathrm{ml} / \mathrm{min}) ; \mathrm{Ht}$, hematocrit; $\mathrm{FF}$, filtration fraction; $R_{a}$ afferent (arteriolar) resistance (dyne/s per $\mathrm{cm}^{5}$ ); $R_{\mathrm{e}}$, efferent (arteriolar) resistance (dyne/s per $\mathrm{cm}^{5}$ ); MBP, mean blood pressure calculated as $(2 \times$ diastolic $\mathrm{BP}+$ systolic $\mathrm{BP}) / 3 ; K_{\mathrm{FG}}$, gross filtration coefficient $(\mathrm{s} / \mathrm{mmHg}) ; P_{\text {glo }}$ glomerular hydrostatic pressure $(\mathrm{mmHg}) ; \Delta P_{\mathrm{F}}$, filtration pressure across the glomerular capillaries $(\mathrm{mmHg}) ; P_{\mathrm{BO}}$, hydrostatic pressure in Bowman's space $(10 \mathrm{mmHg}) ; \pi \mathrm{G}$, oncotic pressure within glomerular capillaries $(\mathrm{mmHg}) ; C_{\mathrm{M}}$, plasma protein concentration within the glomerular capillaries (g/dl); TP, total protein concentration $(\mathrm{g} / \mathrm{dl})$.

were performed to evaluate the relationships between $R_{\mathrm{a}}$ and other parameters. All analyses were performed using StatView 5 for Windows (SAS Institute, Inc., Cary, NC, USA). The level of significance was set at $P<0.05$.

\section{Results}

\section{Baseline characteristics}

Baseline characteristics of the 26 patients are shown in Table 2 . The mean age was $59.5 \pm 14.0$ years old and eight patients $(30.8 \%)$ were male. The mean levels of serum creatinine and blood urea nitrogen (BUN) were $0.692 \pm 0.174$ and $14.7 \pm 2.8 \mathrm{mg} / \mathrm{dl}$ respectively and GFR estimated from $C_{\text {in }}$ was $72.7 \pm 18.3 \mathrm{ml} / \mathrm{min}$. The mean blood pressure was normal $(90.5 \pm 10.7 \mathrm{mmHg})$, but 12 patients $(46 \%)$ were receiving antihypertensive therapy with an angiotensin receptor blocker $(n=11)$, angiotensin converting enzyme (ACE) inhibitor $(n=3)$, or a calcium channel blocker $(n=5)$. The plasma glucose and $\mathrm{HbA1c}$ values were $122.6 \pm 34.2 \mathrm{mg} / \mathrm{dl}$ and $7.6 \pm 1.6 \%$ respectively with 21 patients diagnosed with type 2 diabetes mellitus (DM) based on the history of diabetes or on criteria in the Report of the Expert Committee on the Diagnosis and Classification of Diabetes Mellitus. There was no significant difference in GFR between patients with and without type $2 \mathrm{DM}$ (DM vs non-DM: $70.9 \pm 19.0$ vs $80.1 \pm 13.5 \mathrm{ml} / \mathrm{min}$, $P=0.3203)$. All subjects had no physical findings indicating thyroid disease, such as diffuse goiter, and the serum levels of $\mathrm{FT}_{4}, \mathrm{FT}_{3}$, and TSH were within the respective normal ranges of $1.200 \pm 0.182 \mathrm{ng} / \mathrm{ml}$, $2.924 \pm 0.376 \mathrm{pg} / \mathrm{ml}$, and $1.720 \pm 0.885 \mu \mathrm{IU} / \mathrm{ml}$.

\section{Relationship of serum $\mathrm{FT}_{4}, \mathrm{FT}_{3}$, and TSH with $\mathbf{R}_{a}, \mathbf{R}_{e}$, and glomerular hemodynamics}

Serum TSH, even within its normal range, showed a significant positive correlation with $R_{\mathrm{a}}(r=0.609$,
$P=0.0010)$, but no correlation with $R_{\mathrm{e}}(r=0.013$, $P=0.9494$ ) (Fig. 1), and had significant negative correlations with $\mathrm{C}_{\mathrm{in}}$-based GFR $(r=-0.505$, $P=0.0086)$, RPF $(r=-0.456, P=0.0192)$, and RBF $(r=-0.438, P=0.0252)$ (Fig. 2). An age-related increase in serum TSH has been reported (17), but we found no significant correlation between age and $R_{\mathrm{a}}$ $(r=0.259, P=0.2015)$ or $R_{\mathrm{e}}(r=0.311, P=0.0647)$. Collectively, these data suggest that a subtle change in serum TSH, even within its normal range might suppress glomerular hemodynamics, particularly by increasing vascular resistance at afferent arterioles, independent of age. Neither $\mathrm{FT}_{4}$ nor $\mathrm{FT}_{3}$ showed a significant relationship with $R_{\mathrm{a}}, R_{\mathrm{e}}, \mathrm{C}_{\mathrm{in}}$-based GFR, RPF, or RBF (data not shown).

\section{Relationship of mean blood pressure with $\mathbf{R}_{a}$, $\mathbf{R}_{e}$, and glomerular hemodynamics}

Mean blood pressure was significantly positively correlated with $R_{\mathrm{a}}(r=0.422, P=0.0319)$, but not with $R_{\mathrm{e}}(r=0.043, P=0.8361)$ (Fig. 3), suggesting that an increase in blood pressure might cause an increase in $R_{\mathrm{a}}$, but not in $R_{\mathrm{e}}(15,16)$. Mean blood pressure did not correlate significantly with RPF $(r=0.057, P=0.7812)$ or RBF $(r=0.105, P=0.6098)$, or with serum $\mathrm{FT}_{4} \quad(r=0.207, \quad P=0.3106)$, $\mathrm{FT}_{3} \quad(r=0.194, \quad P=0.4004)$, or TSH $(r=0.064$, $P=0.7648)$. There was no significant difference in $R_{\mathrm{a}}$ between patients treated with a renin-angiotensinaldosterone (RAS) system inhibitor and those who did not receive a RAS inhibitor $(6406.8 \pm 4540.9$ vs 5572.2 $\pm 3592.6, P=0.6080)$.

Table 2 Clinical characteristics of patients.

\begin{tabular}{lcc}
\hline & $\begin{array}{c}\text { Value } \\
\text { Item }\end{array}$ & Range \\
\hline Age & $59.5 \pm 14.0$ & $22-78$ \\
Gender (m/f) & $8 / 18$ & \\
Type 2 diabetes mellitus (yes/no) & $21 / 5$ & \\
BMl $\left(\mathrm{kg} / \mathrm{m}^{2}\right.$ ) & $26.2 \pm 4.5$ & $18.3-35.0$ \\
Mean blood pressure (mmHg) & $90.5 \pm 10.7$ & $71.3-119.3$ \\
Systolic blood pressure $(\mathrm{mmHg})$ & $127.1 \pm 16.7$ & $98-162$ \\
Diastolic blood pressure (mmHg) & $72.2 \pm 0.9$ & $54-100$ \\
Serum creatinine (mg/dl) & $0.692 \pm 0.174$ & $0.4-0.98$ \\
Blood urea nitrogen (mg/dl) & $14.7 \pm 2.8$ & $9.0-21.0$ \\
Inulin clearance (ml/min) & $72.7 \pm 18.3$ & $24.7-106.8$ \\
PAH clearance(ml/min) & $362.6 \pm 145.2$ & $131-842$ \\
Albumin (g/dl) & $4.1 \pm 0.4$ & $3.0-4.7$ \\
Plasma glucose (mg/dl) & $122.6 \pm 34.2$ & $57.0-185.0$ \\
HbA1c (\%) & $7.6 \pm 1.6$ & $4.8-10.5$ \\
TSH $(\mu l \mathrm{ll} / \mathrm{ml})$ & $1.720 \pm 0.885$ & $0.69-4.30$ \\
$\mathrm{FT}_{3}(\mathrm{pg} / \mathrm{ml})$ & $2.924 \pm 0.376$ & $2.3-3.91$ \\
$\mathrm{FT}_{4}(\mathrm{ng} / \mathrm{dl})$ & $1.200 \pm 0.182$ & $0.37-1.6$ \\
& & \\
\hline
\end{tabular}

$\mathrm{PAH}$, para-aminohippurate. 
A

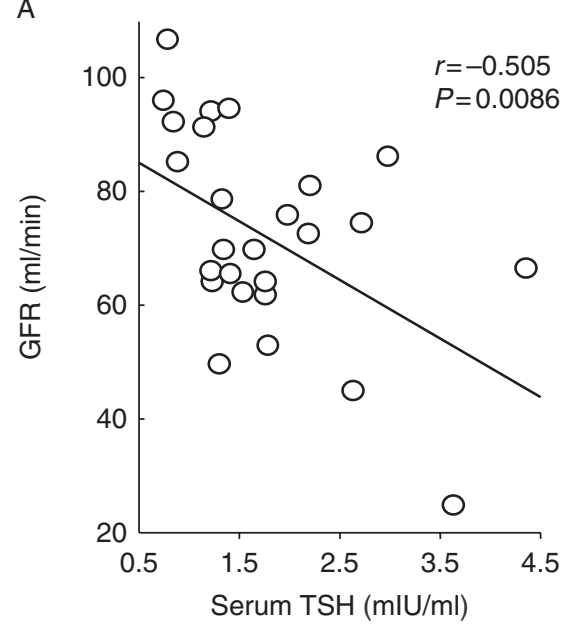

B
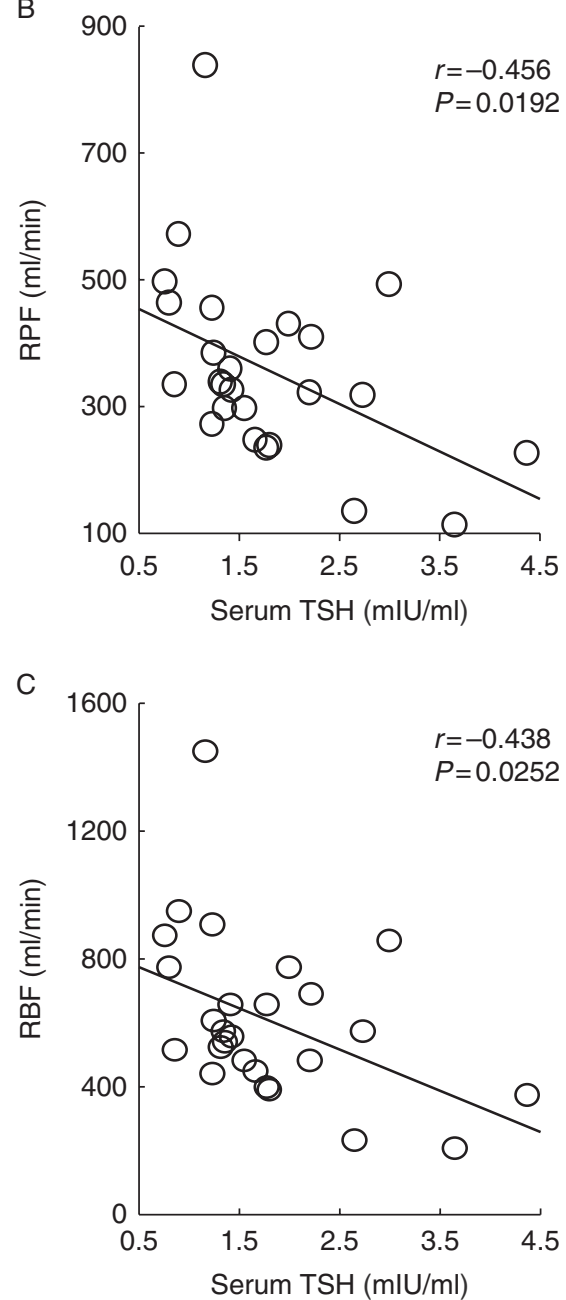

Figure 2 Relationship between serum TSH and glomerular filtration rate (GFR), renal plasma flow (RPF) and renal blood flow (RBF). Serum TSH showed significant negative correlations with $(A)$ glomerular filtration rate (GFR; $r=-0.505, P=0.0086$ ), (B) renal plasma flow (RPF; $r=-0.456, P=0.0192$ ), and $(C)$ renal blood flow (RBF; $r=-0.438, P=0.0252$ ).

\section{Multiple regression analysis of factors independently associated with $\mathbf{R}_{a}$ and $\mathbf{R}_{e}$}

The results of multiple regression analysis to identify factors significantly associated with $R_{\mathrm{a}}$ and $R_{\mathrm{e}}$ are shown in Table 3. In models including serum TSH, age, and mean blood pressure as independent variables, serum TSH alone emerged as a significant factor with a positive association with $R_{\mathrm{a}}$ but had no association with $R_{\mathrm{e}}$.

\section{Discussion}

In this study, we clearly demonstrated that the high serum TSH, even within normal range, as reflected by a subtle increase in TSH within its normal range, was significantly correlated with reduction of GFR, RPF, and $\mathrm{RBF}$, estimated from $\mathrm{C}_{\text {in }}$ and $\mathrm{C}_{\mathrm{PAH}}$. Our results may indicate a possible direct effect of TSH on the kidney, as it has been reported that TSH receptor is also expressed in a variety of extrathyroidal tissues including the kidney (18). Our results may be consistent with the report by Sun et al. (19), who demonstrated that TSH is an independent factor for determining renal function and CKD in normoglycemic euthyroid adults. The underlying mechanism of our results may involve increased vascular resistance at afferent arterioles, based on the significant and independent association of high serum TSH with increased $R_{\mathrm{a}}$, independent of age and mean blood pressure, but not with $R_{\mathrm{e}}$. The parameters for renal hemodynamics were calculated from $\mathrm{C}_{\mathrm{in}}$ and $\mathrm{C}_{\mathrm{PAH}}$, which are independent of creatinine metabolism. Therefore, this shows that the effect of low thyroid function on creatinine metabolism in muscle and the resultant changes of serum and urinary creatinine levels are not responsible for low GFR in patients with low normal thyroid function. Causality is not conclusively determined, but it is likely that low thyroid function may reduce GFR, RPF, and RBF by increasing $R_{\mathrm{a}}$, as it has been shown that $\mathrm{T}_{4}$ replacement therapy increases GFR in hypothyroid patients (20) and that treatment of Graves' patients with anti-thyroid drugs decreases GFR (21). Our study may also be consistent with the results that TSH positively correlated with creatinine in hypothyroid subjects (22). Low cardiac output may also be associated with decreased RBF in hypothyroidism (23).

We have previously reported a significant increase in arterial wall stiffening, as represented by an increase in PWV, in patients with subclinical hypothyroidism (24) and clinically overt hypothyroidism (25). As the current study raised the possibility that CKD might develop due to low thyroid function, it is possible that development of CKD in patients with low thyroid function (but within the normal range) might be an early event that accelerates atherosclerotic changes, which develop no earlier than subclinical hypothyroidism (26). Therefore, 


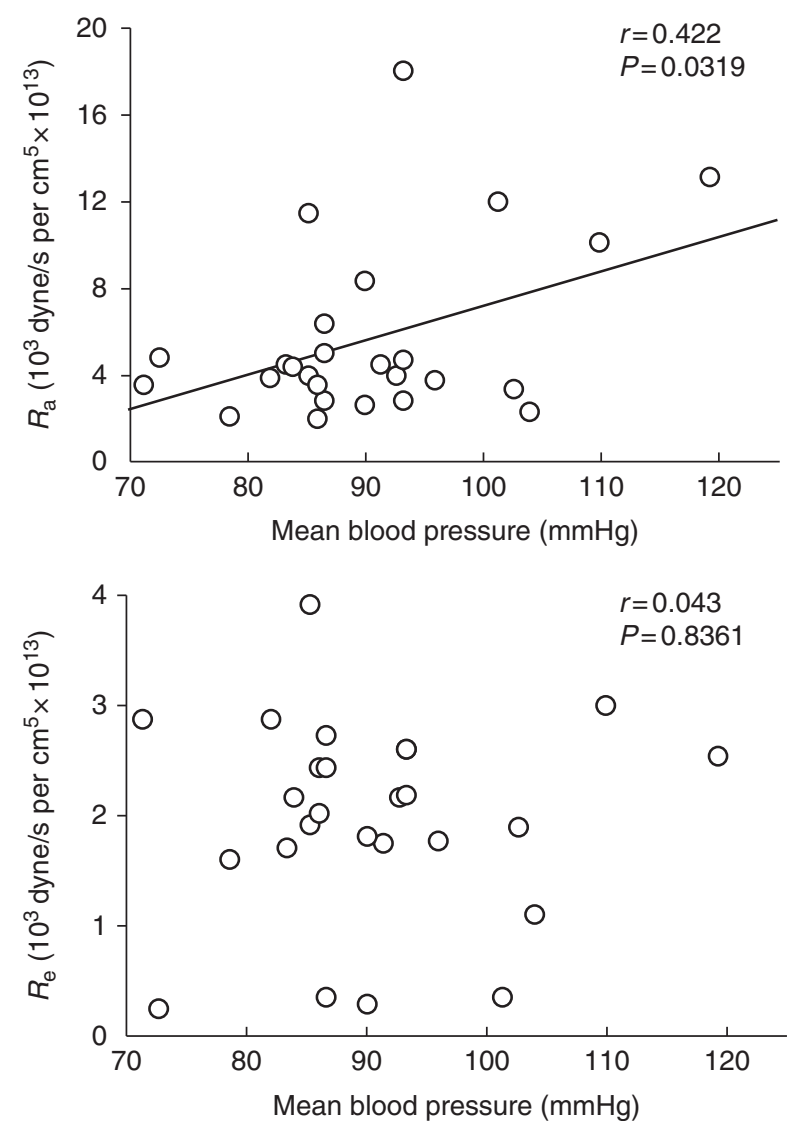

Figure 3 Relationship between mean blood pressure and afferent arteriolar resistance and efferent arteriolar resistance. Mean blood pressure had a significant positive correlation with afferent arteriolar resistance $\left(R_{\mathrm{a}} ; r=0.422, P=0.0319\right)$ but showed no correlation with efferent arteriolar resistance $\left(R_{e} ; r=0.043, P=0.8361\right)$.

CKD due to low thyroid function may contribute to development of atherosclerotic changes in subclinical hypothyroidism.

In humans, it is not possible to measure glomerular hemodynamic variables directly; thus, the evidence for this pathogenetic mechanism is indirect and is based mainly on therapeutic interventions that are believed to lower glomerular pressure and filtration, such as a lowprotein diet or ACE inhibitors (27). However, in 1951, Gomez (15) published a series of formulae for indirect evaluation of glomerular hemodynamics in humans. These formulae (slightly modified for animal studies) have been used to calculate glomerular hemodynamics in various conditions, including untreated and treated essential hypertension $(15,28)$, rat models of hypertension (28), renovascular hypertension (29), primary aldosteronism (30), and supraventricular tachycardia (31). In this study, on the basis of these formulae, we found that reduced GFR, RPF, and RBF mainly result from increased vascular resistance at afferent arterioles, as reflected by increased $R_{\mathrm{a}}$.
Table 3 Multiple regression analysis of factors with a potential independent association with afferent arteriolar resistance $\left(R_{\mathrm{a}}\right)$ and efferent arteriolar resistance $\left(R_{\mathrm{e}}\right)$.

\begin{tabular}{lcccrcr}
\hline & \multicolumn{3}{c}{$\boldsymbol{R}_{\mathbf{a}}$} & & \multicolumn{2}{c}{$\boldsymbol{R}_{\mathbf{e}}$} \\
\cline { 2 - 3 } \cline { 5 - 6 } & $\beta$ & \multicolumn{1}{c}{$P$} & & \multicolumn{1}{c}{$\beta$} & $P$ \\
\hline Serum TSH & 0.528 & 0.0042 & & -0.103 & 0.6395 \\
Age & 0.064 & 0.6977 & & 0.294 & 0.1846 \\
Mean blood & 0.304 & 0.706 & & -0.024 & 0.9111 \\
$\quad$ pressure & & & & & 0.0777 \\
$R^{2}$ & 0.330 & & & \\
\hline
\end{tabular}

This study has some limitations. First, the study was performed in a small number of Japanese patients, and a large-scale study is needed to confirm that the subtle reduction of thyroid function within euthyroidism increases $R_{\mathrm{a}}$ and decreases $C_{\mathrm{in}}$. Secondly, some of the patients took antihypertensive drugs, including RAS inhibitors. However, these inhibitors mainly affect efferent arterioles and decrease $R_{\mathrm{e}}(32,33)$, and their use cannot explain the increase in $R_{\mathrm{a}}$. Thirdly, diabetic patients were included in the study. However, in our recent study, glycemic control indices were significantly positively associated with $R_{\mathrm{e}}$, but not with $R_{\mathrm{a}}$ (data not shown). Also, patients with DM did not show microalbuminuria and there was no significant difference in GFR between diabetic and non-diabetic patients, which indicates that diabetic nephropathy did not influence the results. Lastly, the formulae used to evaluate glomerular hemodynamics in humans are based on several assumptions, but many studies have validated the clinical utility of these formulae, as described earlier.

In conclusion, the results of the study demonstrate that low thyroid function, even within the normal range, is associated with reduced GFR, RPF, and RBF, resulting from increased $R_{\mathrm{a}}$, and thus suggest that development of CKD might promote atherosclerotic changes in the early stage of hypothyroidism.

\section{Declaration of interest}

The authors declare that there is no conflict of interest that could be perceived as prejudicing the impartiality of the research reported.

\section{Funding}

This research did not receive any specific grant from any funding agency in the public, commercial or not-for-profit sector.

\section{References}

1 Evered DC, Tunbridge WM, Hall R, Appleton D, Brewis M, Clark F, Manuel P \& Young E. Thyroid hormone concentrations in a large scale community survey. Effect of age, sex, illness and medication. Clinica Chimica Acta 197883 223-229. (doi:10.1016/00098981(78)90110-9)

2 Cappola AR \& Ladenson PW. Hypothyroidism and atherosclerosis. Journal of Clinical Endocrinology and Metabolism $2003 \mathbf{8 8}$ 2438-2444. (doi:10.1210/jc.2003-030398) 
3 Sawin CT, Chopra D, Azizi F, Mannix JE \& Bacharach P. The aging thyroid. Increased prevalence of elevated serum thyrotropin levels in the elderly. Journal of the American Medical Association 1979242 247-250. (doi:10.1001/jama.1979.03300030019013)

4 Fliser D, Zeier M, Nowack R \& Ritz E. Renal functional reserve in healthy elderly subjects. Journal of the American Society of Nephrology 19933 1371-1377.

5 Imaizumi M, Akahoshi M, Ichimaru S, Nakashima E, Hida A, Soda M, Usa T, Ashizawa K, Yokoyama N, Maeda R et al. Risk for ischemic heart disease and all-cause mortality in subclinical hypothyroidism. Journal of Clinical Endocrinology and Metabolism 200489 3365-3370. (doi:10.1210/jc.2003-031089)

6 Takami T \& Shigemasa M. Efficacy of various antihypertensive agents as evaluated by indices of vascular stiffness in elderly hypertensive patients. Hypertension Research 200326 609-614. (doi:10.1291/hypres.26.609)

7 Okabe R, Inaba M, Sakai S, Ishimura E, Moriguchi A, Shoji T \& Nishizawa Y. Increased arterial stiffening and thickening in the paretic lower limb in patients with hemiparesis. Clinical Science 2004106 613-618. (doi:10.1042/CS20030387)

8 Nagasaki T, Inaba M, Kumeda Y, Hiura Y, Shirakawa K, Yamada S, Henmi Y, Ishimura E \& Nishizawa Y. Increased pulse wave velocity in subclinical hypothyroidism. Journal of Clinical Endocrinology and Metabolism 200691 154-158. (doi:10.1210/jc.2005-1342)

9 Vargas F, Moreno JM, Rodriguez-Gomez I, Wangensteen R, Osuna A, Alvarez-Guerra M \& Garcia-Estan J. Vascular and renal function in experimental thyroid disorders. European Journal of Endocrinology 2006154 197-212. (doi:10.1530/eje. 1.02093)

10 Kreisman SH \& Hennessey JV. Consistent reversible elevations of serum creatinine levels in severe hypothyroidism. Archives of Internal Medicine 1999159 79-82. (doi:10.1001/archinte.159. 1.79)

11 Horio M, Imai E, Yasuda Y, Hishida A \& Matsuo S. Simple sampling strategy for measuring inulin renal clearance. Clinical \& Experimental Metastasis 200913 50-54. (doi:10.1007/s10157008-0084-z)

12 Fliser D, Dikow R, Demukaj S \& Ritz E. Opposing effects of angiotensin II on muscle and renal blood flow under euglycemic conditions. Journal of the American Society of Nephrology 200011 2001-2006. (doi:10.1007/s10157-009-0174-6)

13 Kimata S, Mizuguchi K, Hattori S, Teshima S \& Orita Y. Evaluation of a new automated, enzymatic inulin assay using D-fructose dehydrogenase. Clinical $\mathcal{E}$ Experimental Metastasis 200913 341-349.

14 Turner ST \& Reilly SL. Fallacy of indexing renal and systemic hemodynamic measurements for body surface area. American Journal of Physiology $1995 \mathbf{2 6 8}$ R978-R988.

15 Gomez DM. Evaluation of renal resistances, with special reference to changes in essential hypertension. Journal of Clinical Investigation 195130 1143-1155. (doi:10.1172/JCI102534)

16 Guidi E, Cozzi MG, Minetti EE, Civati G, Busnach G \& Brando B. Effect of familial hypertension on glomerular hemodynamics and tubulo-glomerular feedback after uninephrectomy. American Journal of Hypertension $2001 \quad 14$ 121-128. (doi:10.1016/ S0895-7061(00)01238-3)

17 Over R, Mannan S, Nsouli-Maktabi H, Burman KD \& Jonklaas J. Age and the thyrotropin response to hypothyroxinemia. Journal of Clinical Endocrinology and Metabolism 201095 3675-3683. (doi:10.1210/jc.2010-0281)

18 Williams GR. Extrathyroidal expression of TSH receptor. Annales d'Endocrinologie 201172 68-73. (doi:10.1016/j.ando.2011. 03.006)

19 Sun MT, Hsiao FC, Su SC, Pei D \& Hung YJ. Thyrotropin as an independent factor of renal function and chronic kidney disease in normoglycemic euthyroid adults. Endocrine Research 201237 110-116. (doi:10.3109/07435800.2011.640374)
20 Franco M, Bobadilla NA, Suarez J, Tapia E, Sanchez L \& HerreraAcosta J. Participation of adenosine in the renal hemodynamic abnormalities of hypothyroidism. American Journal of Physiology 1996270 F254-F262.

21 den Hollander JG, Wulkan RW, Mantel MJ \& Berghout A. Correlation between severity of thyroid dysfunction and renal function. Clinical Endocrinology 200562 423-427. (doi:10.1111/ j.1365-2265.2005.02236.x)

22 Saini V, Yadav A, Arora MK, Arora S, Singh R \& Bhattacharjee J. Correlation of creatinine with TSH levels in overt hypothyroidism - a requirement for monitoring of renal function in hypothyroid patients? Clinical Biochemistry 201245 212-214. (doi:10.1016/j. clinbiochem.2011.10.012)

23 Iglesias $\mathrm{P} \&$ Diez JJ. Thyroid dysfunction and kidney disease. European Journal of Endocrinology $2009 \mathbf{1 6 0} 503-515$. (doi:10. 1530/EJE-08-0837)

24 Nagasaki T, Inaba M, Yamada S, Shirakawa K, Nagata Y, Kumeda Y, Hiura Y, Tahara H, Ishimura E \& Nishizawa Y. Decrease of brachial-ankle pulse wave velocity in female subclinical hypothyroid patients during normalization of thyroid function: a double-blind, placebo-controlled study. European Journal of Endocrinology 2009160 409-415. (doi:10.1530/EJE08-0742)

25 Nagasaki T, Inaba M, Henmi Y, Kumeda Y, Ueda M, Tahara H, Sugiguchi S, Fujiwara S, Emoto M, Ishimura E et al. Decrease in carotid intima-media thickness in hypothyroid patients after normalization of thyroid function. Clinical Endocrinology 2003 59 607-612. (doi:10.1046/j.1365-2265.2003.01893.x)

26 Asvold BO, Bjoro T \& Vatten LJ. Association of thyroid function with estimated glomerular filtration rate in a population-based study: the HUNT study. European Journal of Endocrinology 2011 164 101-105. (doi:10.1530/EJE-10-0705)

27 Mackenzie HS \& Brenner BM. Current strategies for retarding progression of renal disease. American Journal of Kidney Diseases 199831 161-170. (doi:10.1053/ajkd.1998.v31.pm9428469)

28 Isshiki T, Amodeo C, Messerli FH, Pegram BL \& Frohlich ED. Diltiazem maintains renal vasodilation without hyperfiltration in hypertension: studies in essential hypertension man and the spontaneously hypertensive rat. Cardiovascular Drugs and Therapy 19871 359-366. (doi:10.1007/BF02209077)

29 Kimura G, London GM, Safar ME, Kuramochi M \& Omae T. Glomerular hypertension in renovascular hypertensive patients. Kidney International 199139 966-972. (doi:10.1038/ki.1991. 122)

30 Nagai T, Kimura G, Matsuoka H, Sanai T, Imanishi M, Kawano Y, Kojima S, Yoshida K, Abe H, Ashida T et al. Estimation of the intrarenal hemodynamics in patients with primary aldosteronism. Nihon Jinzo Gakkai Shi 198931 235-241.

31 Kojima S, Fujii T, Ohe T, Yoshitomi Y, Kuramochi M, Shimomura K \& Omae T. Glomerular hemodynamics during supraventricular tachycardia. Japanese Heart Journal 199536 429-437. (doi:10. 1536/ihj.36.429)

32 Bakris GL \& Weir MR. Angiotensin-converting enzyme inhibitorassociated elevations in serum creatinine: is this a cause for concern? Archives of Internal Medicine $2000 \mathbf{1 6 0} 685-693$. (doi:10.1001/archinte.160.5.685)

33 Hollenberg NK, Price DA, Fisher ND, Lansang MC, Perkins B, Gordon MS, Williams GH \& Laffel LM. Glomerular hemodynamics and the renin-angiotensin system in patients with type 1 diabetes mellitus. Kidney International 200363 172-178. (doi:10.1046/j. 1523-1755.2003.00701.x

Received 13 January 2013

Revised version received 7 April 2013

Accepted 12 April 2013 